OPEN ACCESS

Edited by: Enrica Strettoi, Italian National Research Council, Italy

Reviewed by: Valeria Marigo, University of Modena and Reggio Emilia, Italy Claudia Gargini, University of Pisa, Italy

*Correspondence: Nicolás Cuenca cuenca@ua.es

Received: 25 August 2015 Accepted: 30 November 2015 Published: 22 December 2015

Citation:

Fernández-Sánchez L, Lax $P$ Campello L, Pinilla I and Cuenca N (2015) Astrocytes and Müller Cell Alterations During Retinal Degeneration in a Transgenic Rat Model of Retinitis Pigmentosa.

Front. Cell. Neurosci. 9:484 doi: 10.3389/fncel.2015.00484

\section{Astrocytes and Müller Cell Alterations During Retinal Degeneration in a Transgenic Rat Model of Retinitis Pigmentosa}

\author{
Laura Fernández-Sánchez ${ }^{1}$, Pedro Lax ${ }^{1}$, Laura Campello ${ }^{1}$, Isabel Pinilla ${ }^{2}$ and \\ Nicolás Cuenca ${ }^{1,3 *}$ \\ ${ }^{1}$ Department of Physiology, Genetics and Microbiology, University of Alicante, Alicante, Spain, ${ }^{2}$ Department of \\ Ophthalmology, Aragon Institute for Health Research, Lozano Blesa University Hospital, Zaragoza, Spain, ${ }^{3}$ Institute Ramón \\ Margalef, University of Alicante, Alicante, Spain
}

Purpose: Retinitis pigmentosa includes a group of progressive retinal degenerative diseases that affect the structure and function of photoreceptors. Secondarily to the loss of photoreceptors, there is a reduction in retinal vascularization, which seems to influence the cellular degenerative process. Retinal macroglial cells, astrocytes, and Müller cells provide support for retinal neurons and are fundamental for maintaining normal retinal function. The aim of this study was to investigate the evolution of macroglial changes during retinal degeneration in $\mathrm{P} 23 \mathrm{H}$ rats.

Methods: Homozygous P23H line-3 rats aged from P18 to 18 months were used to study the evolution of the disease, and SD rats were used as controls. Immunolabeling with antibodies against GFAP, vimentin, and transducin were used to visualize macroglial cells and cone photoreceptors.

Results: In P23H rats, increased GFAP labeling in Müller cells was observed as an early indicator of retinal gliosis. At 4 and 12 months of age, the apical processes of Müller cells in $\mathrm{P} 23 \mathrm{H}$ rats clustered in firework-like structures, which were associated with ring-like shaped areas of cone degeneration in the outer nuclear layer. These structures were not observed at 16 months of age. The number of astrocytes was higher in $\mathrm{P} 23 \mathrm{H}$ rats than in the SD matched controls at 4 and 12 months of age, supporting the idea of astrocyte proliferation. As the disease progressed, astrocytes exhibited a deteriorated morphology and marked hypertrophy. The increase in the complexity of the astrocytic processes correlated with greater connexin 43 expression and higher density of connexin 43 immunoreactive puncta within the ganglion cell layer (GCL) of P23H vs. SD rat retinas.

Conclusions: In the $\mathrm{P} 23 \mathrm{H}$ rat model of retinitis pigmentosa, the loss of photoreceptors triggers major changes in the number and morphology of glial cells affecting the inner retina.

Keywords: astrocytes, müller cells, gliosis, immunolabeling, $\mathrm{P} 23 \mathrm{H}$, retinal remodeling 


\section{INTRODUCTION}

Retinal macroglia, consisting of astrocytes and Müller cells, play key roles in the homeostasis of retinal neurons, keeping the retina healthy, and functioning properly. Müller cells, the largest glial cells in the retina of vertebrates, cover practically the entire retinal thickness (from the outer to the inner limiting membrane) and make contact with both neuronal somata and processes in the entire retina. Müller glial cells are thought to play an essential role in maintaining the structural integrity of the retina and to participate in essential processes, such as glucose metabolism, neurotransmitter uptake, and retinal homeostasis (Reichenbach and Bringmann, 2013; Chong and Martin, 2015). Astrocytes, almost entirely restricted to the retinal nerve fiber layer, have a close relationship with neurons and the major blood vessels. They are commonly thought to play an important part in the proper development and functioning of the vascular system in the retina, including blood flow and the formation of the blood-retinal barrier (BRB) (Coorey et al., 2012; Kur et al., 2012; Klaassen et al., 2013). Both astrocytes and Müller cells are involved in the survival of retinal cells through the release of neurotrophic factors, providing anti-oxidative support, clearing neurotransmitters and ions from the extraneural space and, as in the brain, supporting the formation and removal of synapses. They are also involved in the activation of microglial cells and participate in the regulatory mechanisms of vasodilation and vasoconstriction (Azevedo et al., 2009; Bringmann and Wiedemann, 2012; Coorey et al., 2012; Bringmann et al., 2013; Cuenca et al., 2014; Chong and Martin, 2015; Vecino et al., 2015).

Astrocyte activation and reactive gliosis are common traits in neurodegenerative processes. A hallmark of gliosis is the upregulation of intermediate filament proteins in glial cells, including glial fibrillary acidic protein (GFAP), vimentin, and nestin (Anderson et al., 2008; Luna et al., 2010). Increasing evidence points to both the benefits and adverse effects that reactive gliosis can have on already injured neurons. The neuroprotective effects of activated glial cells include the production of neurotrophic factors, growth factors, and cytokines (Harada et al., 2003; Bringmann et al., 2006), whereas the dysfunction of glial cells in different pathologies of the retina has been linked to retinal swelling and BRB breakdown (Shen et al., 2010; Klaassen et al., 2013). In contrast, chronic gliosis might accelerate neurodegeneration over the course of a chronic illness, resulting in both direct and indirect damage to neurons and the vascular system in the retina. In this context, chronic gliosis exacerbates the progression of the disease, making vessels more permeable, and enhancing the infiltration of toxic compounds (Bringmann et al., 2006; Coorey et al., 2012). Furthermore, in mature retinas, astrocytes, and Müller cells play a role in the neovascularization linked to pathological processes, such as agerelated macular degeneration (AMD), diabetic retinopathy (DR), and retinopathy of prematurity (ROP), as they have been shown to release angiogenic growth factors in the presence of pathogenic stimuli (Penn et al., 2008).

Retinitis pigmentosa (RP) is a heterogeneous group of retinal degenerative disorders with a polymorphic hereditary origin that cause a progressive loss of retinal function, and it represents a major cause of blindness. Approximately $20-25 \%$ of autosomal dominant RP patients exhibit a mutation in the rhodopsin gene, with $\mathrm{P} 23 \mathrm{H}$ being one of the most common rhodopsin mutations (Dryja et al., 1990), accounting for about one-third of such cases in the USA (Dryja et al., 2000). The P23H mutation is now known to provoke the retention and misfolding of rhodopsin in the endoplasmic reticulum (Kaushal and Khorana, 1994). Some studies have also pointed to a mechanism for RP in which cellular stress triggers an inflammatory response, which is followed by retinal remodeling, and the final common pathway of programmed photoreceptor cell death, i.e., apoptosis (Remé et al., 1998; Illing et al., 2002; Marc et al., 2003; Jones et al., 2012; Cuenca et al., 2014). Similar mechanisms have been found in other forms of retinal degeneration, such as glaucoma, DR, and AMD (Cuenca et al., 2014).

Transgenic $\mathrm{P} 23 \mathrm{H}$ rats have been engineered to mimic human P23H RP (Dryja et al., 1990, 2000). Although they initially exhibit normal cone function, these rats develop a progressive rod dysfunction that is consistent in broad terms with the clinical findings reported for human patients with P23H RP (Berson et al., 1991; Machida et al., 2000; Cuenca et al., 2004; Pinilla et al., 2005). Photoreceptor loss has been observed to accompany degeneration of the inner retina (Marc et al., 2003; Cuenca et al., 2004, 2014; Jones and Marc, 2005; Puthussery and Taylor, 2010; Jones et al., 2012), in addition to considerable degeneration of retinal ganglion cells (Jones et al., 2003; García-Ayuso et al., 2010; Kolomiets et al., 2010).

Considering the key role of glial cells in maintaining the structure, function, and survival of retinal neurons, it is important to expand our understanding of the cellular changes in glial cells associated with retinal injuries and neurodegenerative diseases. The aim of this study was to investigate the evolution of macroglial changes during retinal degeneration in RP and to evaluate the role of macroglia in inner retina remodeling after photoreceptor death. This study uses albino $\mathrm{P} 23 \mathrm{H}$ rats at different ages as animal models of RP.

\section{MATERIALS AND METHODS}

\section{Animals}

Homozygous albino $\mathrm{P} 23 \mathrm{H}$ line three rats $(n=26)$ obtained from Dr. M. LaVail (UCSF) were used as a model of RP. Normal SD rats $(n=26)$ obtained from Harlan Laboratories (Barcelona, Spain) were used as wild-type controls. All animals were bred in a colony at the University of Alicante, Spain, and maintained under controlled humidity $(60 \%)$, temperature $\left(23 \pm 1^{\circ} \mathrm{C}\right)$ and photoperiod (LD 12:12) conditions. Light was provided by two fluorescent lamps, with an intensity of 350-400 lux at cage level. Dry food and water were made available ad libitum. All animals were housed, handled and the procedures carried out according to Project License UA-2013-07-22, approved by the Ethic Committee for Animal Experiment from the University of Alicante. All procedures were performed according to current regulations regarding the use of laboratory animals (NIH, ARVO, and European Directive 2010/63/UE), which are intended to limit 
both animal suffering and the number of animals required for experimentation.

\section{Retinal Histology \\ Retinal Sections}

Animals were sacrificed in the morning, between 10:00 a.m. and 12:00 p.m., by administering a lethal dose of pentobarbital. After marking the dorsal margin of the limbus with a stitch, the eyes were enucleated, fixed in $4 \%(\mathrm{w} / \mathrm{v})$ paraformaldehyde $1 \mathrm{~h}$ at room temperature (RT), washed and then sequentially cryoprotected in 15,20 , and $30 \%$ sucrose. The cornea, lens, and vitreous body were removed, and the eyecups were processed for vertical sections or whole mounts. For cryostat sections, eyecups were frozen in OCT with liquid nitrogen. Fourteen-micrometer-thick sections were then obtained using a Leica CM 1900 cryostat (Leica Microsystems, Wetzlar, Germany) mounted on Superfrost Plus slides (Menzel GmbH \& Co KG, Braunschweig, Germany) and air-dried. Before further processing, the slides were washed three times in phosphate buffer $(\mathrm{PB})$, and then treated with blocking solution (10\% normal donkey serum in PB plus $0.5 \%$ TritonX-100) for $1 \mathrm{~h}$.

\section{Retinal Immunofluorescence}

In order to objectively compare them, retinas from $\mathrm{P} 23 \mathrm{H}$ and SD rats were fully processed in parallel. All primary antibodies and lectins used in this work (summarized in Table 1) have been previously used in other studies and have been well characterized by us and other authors with regard to the specific cell type molecular markers. Sections and whole mount retinas were either single- or double-immunostained at room temperature overnight or for 3 days, respectively, using combinations of antibodies targeting distinct molecular markers. The dilutions in PB with $0.5 \%$ Triton $\mathrm{X}-100$ are indicated in Table 1. Afterwards, Alexa Fluor 488 (green)-conjugated anti-rabbit IgG and/or Alexa Fluor 555 (red)-conjugated anti-mouse IgG donkey secondary antibodies from Molecular Probes (Eugene, OR) were added at a dilution rate of $1: 100$ for $1 \mathrm{~h}$ for sections and overnight for whole mount retinas. TO-PRO-3 iodide (Molecular Probes) was used as a nuclear marker. Finally, the retinas were washed in PB, mounted in Citifluor (Citifluor Ltd, London, UK) and coverslipped for viewing with laser-scanning confocal microscopy on a Leica TCS SP2 system (Leica Microsystems). Immunohistochemical controls were carried out by omitting either the primary or secondary antibodies. The resulting images from the control and experimental subjects were processed in parallel with Adobe Photoshop 10.0 software (Adobe Systems Inc, San José, CA, USA).

\section{Astrocyte Quantification}

Astrocytes were quantified on whole-mount retinas at different ages. Immunolabeling against GFAP and the nuclear marker TO-PRO-3 were used to identify astrocytes. Lectin was used to visualize blood vessels. Twelve representative regions, each measuring $0.227 \mathrm{~mm}^{2}$, were analyzed from each retina: six equidistant regions on the superior-inferior axis and six fields on the temporal-nasal axis. This ensured representative sampling of the peripheral, medial and central zones of the upper, lower, temporal, and nasal quadrants of each retina. In all 12 regions, each astrocyte cell body was manually counted in two adjacent confocal images and the cell density values were averaged. To avoid overestimation of astrocyte density, only GFAP-positive cells with a well-defined nucleus were included in the count. At least three rats were used for each experimental group.

\section{Immunoblotting}

GFAP and connexin 43 protein expression was assessed using Western blotting on $\mathrm{P} 23 \mathrm{H}$ and $\mathrm{SD}$ rat retinas at 4 and 12 months of age (four rats per experimental group). Briefly, proteins were extracted and subjected to immunoblotting analysis. Proteins ( $30 \mu \mathrm{g} /$ lane) were resolved by SDS-PAGE on $12 \%$ polyacrylamide gels and electrotransferred to nitrocellulose membranes (GE Healthcare, Buckinghamshire, UK). Membranes were blocked in $5 \%$ bovine serum albumin (BSA) diluted in $25 \mathrm{mM}$ Tris ( $\mathrm{pH} 8.0$ ), $150 \mathrm{mM} \mathrm{NaCl}, 2.7 \mathrm{mM} \mathrm{KCl}$ (TBS) with $0.1 \% \mathrm{v} / \mathrm{v}$ Tween 20 for $2 \mathrm{~h}$. Afterwards, membranes were probed at $4^{\circ} \mathrm{C}$ overnight with rabbit polyclonal GFAP or connexin 43 antibodies diluted in TBS, and with mouse monoclonal GAPDH antibodies (see working dilutions on Table 1). After incubation with primary antibodies,

TABLE 1 | Primary antibodies and lectins used in this work.

\begin{tabular}{|c|c|c|c|c|c|}
\hline \multirow[t]{2}{*}{ Molecular marker (initials) } & \multirow[t]{2}{*}{ Antibody/lectin } & \multirow[t]{2}{*}{ Company } & \multirow[t]{2}{*}{ Catalog ref. } & \multicolumn{2}{|c|}{ Working dilution } \\
\hline & & & & IHC & WB \\
\hline Glial fibrillary acidic protein (GFAP) & Mouse, G-A-5 & Sigma & G 3893 & $1: 500$ & - \\
\hline Glial fibrillary acidic protein (GFAP) & Rabbit, polyclonal & Dako & N1506 & $1: 50$ & $1: 1000$ \\
\hline Transducin, Gac subunit (Gt) & Rabbit, polyclonal & Cytosignal & PAB-00801-G & $1: 200$ & - \\
\hline Vimentin & Mouse, V9 & DAKOCytomation & M0725 & $1: 100$ & - \\
\hline Connexin 43 (Cx43) & Rabbit, polyclonal & Sigma & C 6219 & $1: 1000$ & $1: 10000$ \\
\hline Griffonia simplicifolia $\mathrm{IB}_{4}\left(\mathrm{GS}-\mathrm{IB}_{4}\right)$ & Isolectin $\mathrm{IB}_{4}$ & Invitrogen & I21411 & $1: 100$ & - \\
\hline Collagen type IV & Goat, polyclonal & Millipore & AB769 & $1: 100$ & - \\
\hline Glyceraldehyde-3-phosphate dehydrogenase (GAPDH) & Mouse, $6 \mathrm{C5}$ & Millipore & MAB374 & - & $1: 10000$ \\
\hline
\end{tabular}

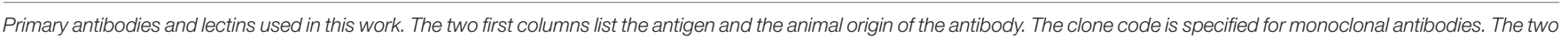

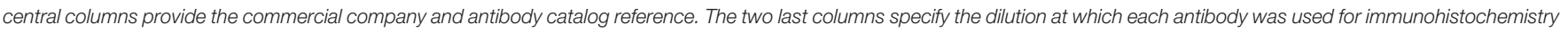
(IHC) or immunoblotting (WB). 
the membranes were incubated at room temperature for $1 \mathrm{~h}$ with horseradish peroxidase-conjugated goat anti-rabbit or goat antimouse (Pierce, Rockford, IL, USA) IgG at a 1:10,000 dilution. Detection was performed by enhanced chemiluminescence using the SuperSignal West Dura system (Pierce).

Western blot films were digitized using a scanner in transparency mode at $300 \mathrm{dpi}$ and 16 bits gray scale. Densitometric quantitation of protein bands was accomplished using the Quantity One software from BioRad (Hercules, CA, USA), and the values obtained for each protein were normalized to GAPDH levels. For each quantified protein, we analyzed the results of at least two independent experiments.

\section{Statistical Analysis}

A Two-way ANOVA was used to evaluate the effects of genotype (SD vs. $\mathrm{P} 23 \mathrm{H})$ and age (P18 to 16 months), alone and in combination. When the level of significance was 0.05 or less, post-hoc pairwise comparisons using Bonferroni's test were performed. Normal distribution and homogeneity of variance were determined for the categories of the previously defined variables. Data are reported as mean \pm SEM. Values of $P<$ 0.05 were considered to be statistically significant. All statistical analyses were performed using SPSS 15.0 software (Statistical Package for Social Sciences, Chicago, IL, USA). All counts were made by two trained observers, using a blind methodology.

\section{RESULTS}

\section{Astrocyte Morphology and Distribution in Normal and Degenerating Rat Retinas}

$\mathrm{P} 23 \mathrm{H}$ rat retinas undergo neurodegenerative changes associated with the progression of the disease. To assess the evolution of astrocyte changes during retinal degeneration, the cell density and morphology of retinal astrocytes were studied at different ages in normal and diseased retinas through the immunocytochemical localization of GFAP. Figure 1 illustrates the distribution and cell density of astrocytes in whole-mounted retinas from SD (Figures 1A,B) and P23H (Figures 1C-F) rats. In normal and diseased retinas, astrocytes were distributed in a plexus located on the ganglion cell layer (GCL). In P23H rat retinas, GFAP-positive Müller cell end-feet were observed at the GCL from P120 to P480 (Figures 1D-F, arrowheads).

Astrocyte quantification showed that astrocyte density gradually increased from the periphery toward the central area of the retina in both $\mathrm{SD}$ and $\mathrm{P} 23 \mathrm{H}$ rats at all ages analyzed (Figures $\mathbf{2 B}, \mathbf{D}, \mathbf{F}, \mathbf{H}$ ). In addition, the astrocyte density was higher in the temporal and superior areas of the retina (Figures 2A,C,E,G). In both SD and $\mathrm{P} 23 \mathrm{H}$ rats, astrocyte density was significantly lower in adults as compared to P18 aged rats (ANOVA, Bonferroni's test, $P<0.001$; Figure 2I), and the mean density of astrocytes increased slightly from P120 to P480 in both $\mathrm{SD}$ and $\mathrm{P} 23 \mathrm{H}$ rats, with significant differences between P120 and $\mathrm{P} 480$ SD rats (ANOVA, Bonferroni's test, $P<0.01$ ). On the other hand, a significant increase in astrocyte cell numbers was found in $\mathrm{P} 120$ and $\mathrm{P} 360 \mathrm{P} 23 \mathrm{H}$ rat retinas, as compared to control $\mathrm{SD}$ rats (ANOVA, Bonferroni's test, $P<0.05$; Figure 2I), with significant differences in all retinal regions analyzed (ANOVA, Bonferroni's test, $P<0.05$; Figures $2 \mathbf{C}-\mathbf{F}$ ).

In both normal and diseased retinas, astrocytes showed the characteristic morphology, with flattened cell body and a series of fibrous radiating processes. As illustrated in Figure 3, astrocyte processes, and even occasionally, astrocyte cell bodies were intimately associated with the blood vessels of the superficial retinal vascular plexus, with astrocyte end-feet encircling endothelial cells (Figures 3A-C, arrowheads). In P23H rats, astrocytic hyperplasia was associated to astrocyte process hypertrophy accompanied by increased GFAP immunoreactivity. Interactions between astrocyte cell bodies and blood vessels were less evident (Figure 3D) in more advanced stages of degeneration (P480).

In 12- and 18-month-old SD rat retinas, astrocytes with normal morphology and distribution were closely associated with typical retinal blood vessels (Figures 4A,C). However, at these ages, $\mathrm{P} 23 \mathrm{H}$ rats showed a progressive disruption of the superficial vascular plexus, exhibiting tortuous vessels (Figures 4B,D). Blood vessels were significantly regressed, and loops largely degenerated. Moreover, $\mathrm{P} 23 \mathrm{H}$ rat retinas showed the formation of blood vessel tangles at 12 (Figure 4E, arrows) and 18 (Figure 4F, arrows) months of age. Figures 4B,D show that superficial vascular plexus degeneration was associated with the loss of normal morphology in astrocyte cells.

\section{Increase of Connexin 43 Immunofluorescence in P23H Rat Retinas}

Connexin $43(\mathrm{Cx} 43)$ is the most abundant gap junction protein in the central nervous system (CNS) including retina, and is expressed mainly on astrocyte processes surrounding blood vessels (Nagy and Rash, 2000; Zahs et al., 2003; Kerr et al., 2010). To determine the relationship between the expression of $\mathrm{Cx} 43$ and astrocytic hyperplasia and hypertrophy in the $\mathrm{P} 23 \mathrm{H}$ rat retina, whole-mounted retinas from $\mathrm{P} 120 \mathrm{SD}$ and $\mathrm{P} 23 \mathrm{H}$ rats were double-labeled with antibodies against $\mathrm{Cx} 43$ and GFAP. In both $\mathrm{SD}$ and $\mathrm{P} 23 \mathrm{H}$ rats, $\mathrm{Cx} 43$-immunoreactive (IR) puncta were located along GFAP-IR astrocyte processes in the GCL (Figure 5). However, the density of $\mathrm{Cx} 43$-IR puncta within the GCL was greater in $\mathrm{P} 23 \mathrm{H}$ (Figures 5C,D) vs. SD rat retinas (Figures 5A,B).

To quantify the differential expression of $\mathrm{Cx} 43$ gap junction proteins in normal and diseased retinas, we performed immunoblotting in 4- and 12-month-old rat retinas from SD and $\mathrm{P} 23 \mathrm{H}$ rats (Figures 5E,F). A 43-kDa band corresponding to $\mathrm{Cx} 43$ protein was observed, which was more intense in $\mathrm{P} 23 \mathrm{H}$ rat retinas than in SD controls (Figure 5E). Antibodies against GAPDH $(36 \mathrm{kDa})$ were used as loading controls for Western blotting experiments. The amount of $\mathrm{Cx} 43$ protein present in each band was densitometrically measured and the value obtained for each sample was normalized to GAPDH levels. The normalized expression levels were significantly upregulated in the diseased rat retinas as compared to controls. Expression fold changes were calculated as the ratio between the $\mathrm{P} 23 \mathrm{H}$ and control normalized values. In particular, Cx43 levels were found to be increased 2.25- and 1.81-fold in the 4- and 12-month-old $\mathrm{P} 23 \mathrm{H}$ rat retinas, 

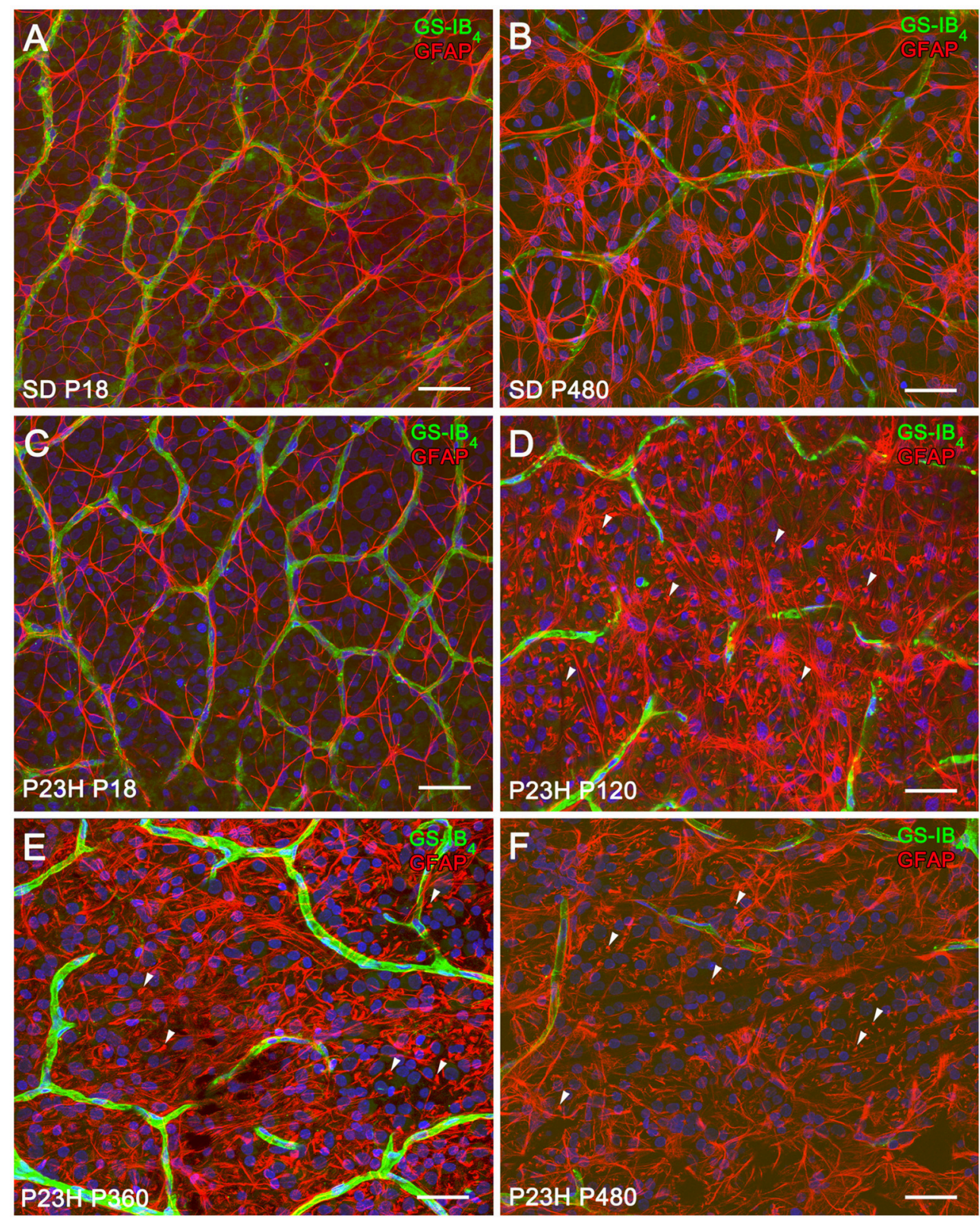

FIGURE 1 | Distribution and density of astrocytes in SD and P23H rat retinas. (A-F) Whole-mounted retinas from SD (A,B) and P23H rats (C-F) at P18 (A,C) P120 (D), P360 (E), and P480 (B,F) showing retinal astrocytes (red) at the nerve fiber layer and blood vessels (green). Nuclei were stained with the nuclear marker TO-PRO 3 (blue). Astrocytes have been labeled with antibodies against GFAP. Blood vessels have been labeled with Griffonia simplicifolia isolectin B4. All images were collected from the medial area of the retina. Note the presence of GFAP positive Müller cell end-feet in P23H rats at P120 (D, arrowheads), P360 (E, arrowheads), and P480 (F, arrowheads). Scale bar: $40 \mu \mathrm{m}$.

respectively, as compared to controls (ANOVA, Bonferroni's test, $P<0.001$ in both cases).

\section{Increased Müller Cell Expression of Vimentin and GFAP in P23H Rat Retinas}

GFAP expression in Müller cells is an indicator of tissue stress, and it has been associated with retinal degeneration, whereas the intermediate filament protein vimentin is ubiquitously expressed in the Müller cells of many mammalian species. Figure 6 shows the immunohistochemical localization of GFAP and vimentin in vertical retinal sections from SD (Figures 6A-C) and $\mathrm{P} 23 \mathrm{H}$ (Figures 6D-L) rats. In Müller cells from normal retinas, vimentin immunostaining was distributed throughout the entire processes, from their end-feet up to the outer retina (Figure 6A), while GFAP immunoreactivity was virtually limited to the inner margin of the retina, colocalizing with astrocytes (Figure 6B). In fact, the colocalization of vimentin and GFAP was negligible in $\mathrm{SD}$ rats (Figure $6 \mathrm{C}$ ). 

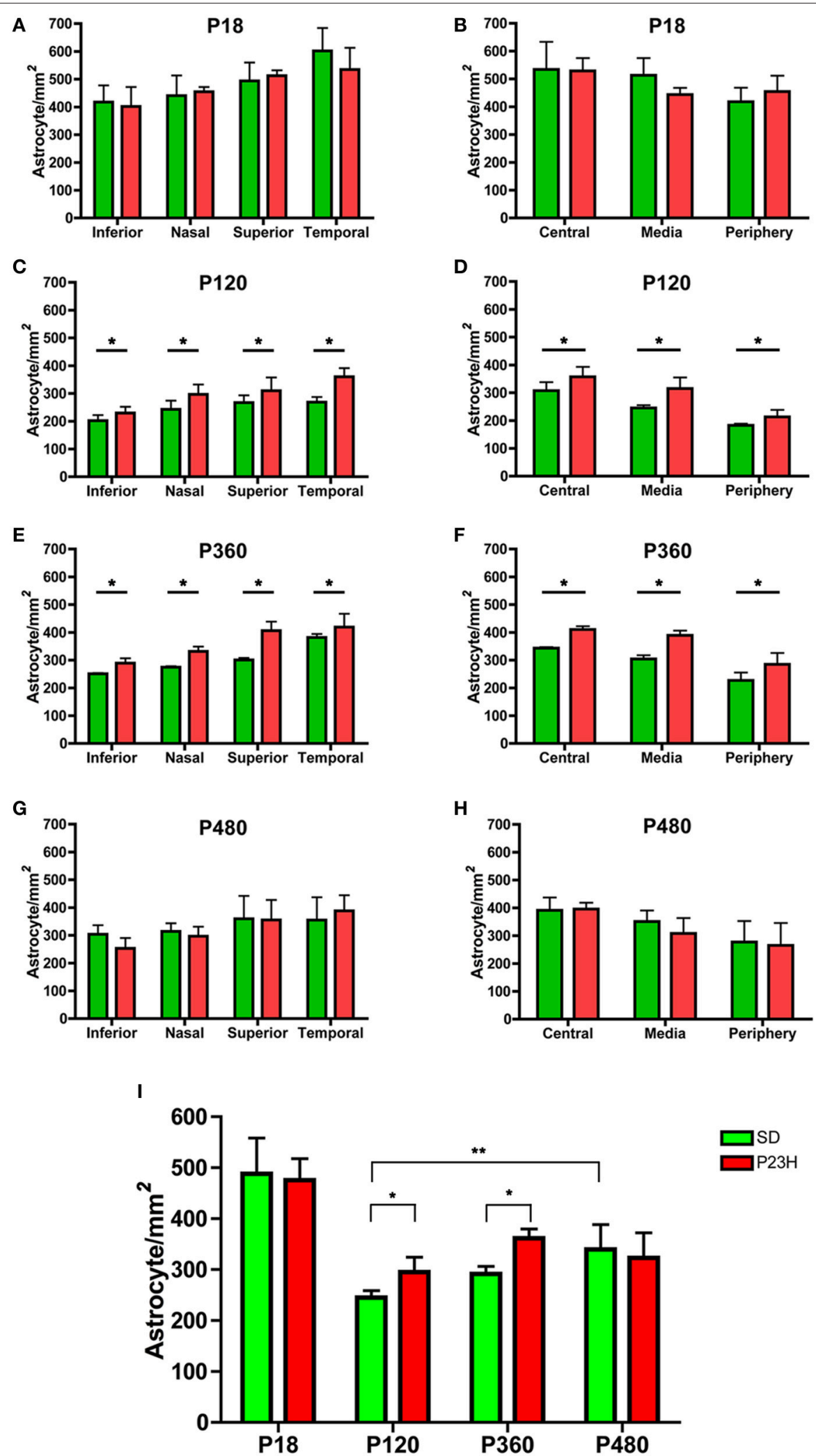

FIGURE 2 | Astrocyte density in SD and P23H rat retinas. Quantification of the cell density of astrocytes in whole-mounted retinas from SD (green) and P23H rats (red). Astrocytes were quantified on representative sampling of the peripheral, medial, and central zones of the upper, lower, temporal, and nasal quadrants of each retina at P18 (A,B), P120 (C,D), P360 (E,F), and P480 (G,H). Mean density values for all representative samplings are represented in (I). Data are reported as mean \pm SEM. ${ }^{*} P<0.05 ;{ }^{*} P<0.01$. 

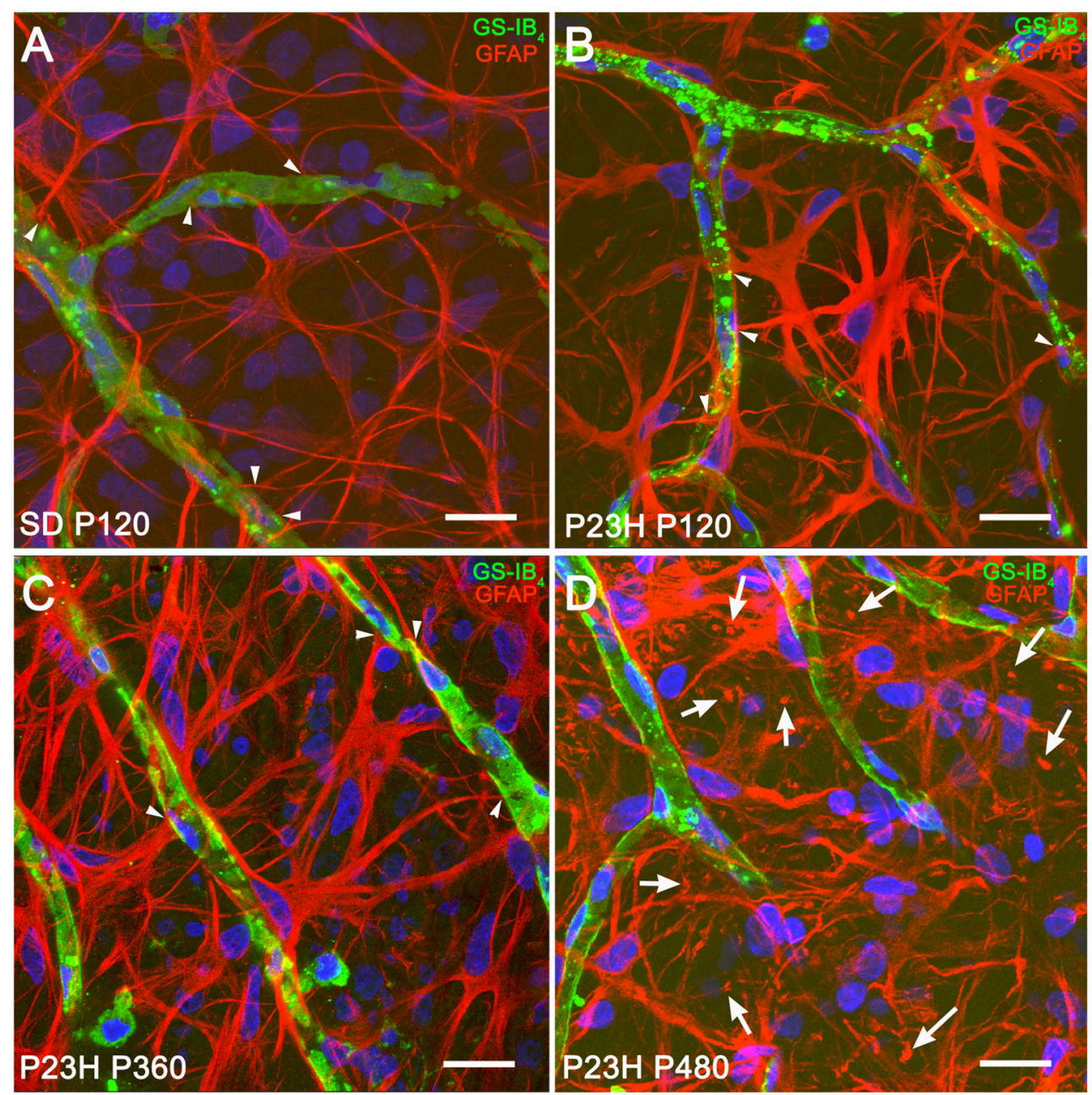

FIGURE 3 | Morphological and structural features of astrocytes in SD and P23H rat retinas. Whole-mounted retinas from a P120 SD rat (A) and P23H rats at P120 (B), P360 (C), and P480 (D), showing retinal astrocytes (red) at the nerve fiber layer and blood vessels (green). Nuclei were stained with the nuclear marker TO-PRO 3 (blue). Astrocytes have been labeled with antibodies against GFAP. Blood vessels have been labeled with G. simplicifolia isolectin B4. All images were collected from the medial area of the retina. Note the presence of GFAP positive Müller cell end-feet in P23H rats at P480 (arrows). Scale bar: $20 \mu \mathrm{m}$.

In $\mathrm{P} 23 \mathrm{H}$ rats, vimentin immunoreactivity within Müller cells was similar to that observed in age-matched control rats (Figures 6A,D,G,J). However, diseased retinas showed intense GFAP immunoreactivity in Müller cells, which exhibited a marked labeling throughout the entire cell (Figures 6E,H,K). Thus, double staining for vimentin and GFAP revealed extensive colocalization of both intermediate filament proteins in these rats (Figures 6F,I,L). Vimentin/GFAP-positive Müller cell apical processes extended into the subretinal space. These glial components expanded, filling areas previously occupied by degenerated photoreceptors (Figures 6D-F, arrows). In agreement with previous reports (Cuenca et al., 2004, 2014), 4month-old $\mathrm{P} 23 \mathrm{H}$ rats showed around two rows of photoreceptor cell bodies in the central area of the retina, whereas 4-monthold SD rats showed around 12 photoreceptor rows in the same area. At 18 months of age and thereafter, photoreceptor cells were virtually absent from $\mathrm{P} 23 \mathrm{H}$ rat retinas (data not shown).
At 12 and 18 months of age, Müller cells have lost their parallel arrangement at IPL level, and their lateral branches had become enlarged and chaotically entangled (Figures 6G-L, arrows).

GFAP protein expression was assessed by Western blotting on $\mathrm{P} 23 \mathrm{H}$ and $\mathrm{SD}$ rat retinas at 4 and 12 months of age (Figures 7A,B). A prominent GFAP band with an estimated SDSPAGE molecular weight of $\sim 55 \mathrm{kDa}$ was observed in $\mathrm{P} 23 \mathrm{H}$ rat retinas compared to SD controls (Figure 7A). Antibodies against GAPDH $(36 \mathrm{kDa})$ were used as loading controls for Western blotting experiments. Thereafter, the amount of GFAP protein present in each band was densitometrically measured and the value obtained for each sample was normalized to GAPDH levels. The normalized expression levels obtained revealed a marked difference of expression between diseased rat retinas and controls (Figure 7B). Expression fold changes were calculated as the ratio between the $\mathrm{P} 23 \mathrm{H}$ and control normalized values. Specifically, we observed a 7.8- and 5.3-fold increase in GFAP expression in 


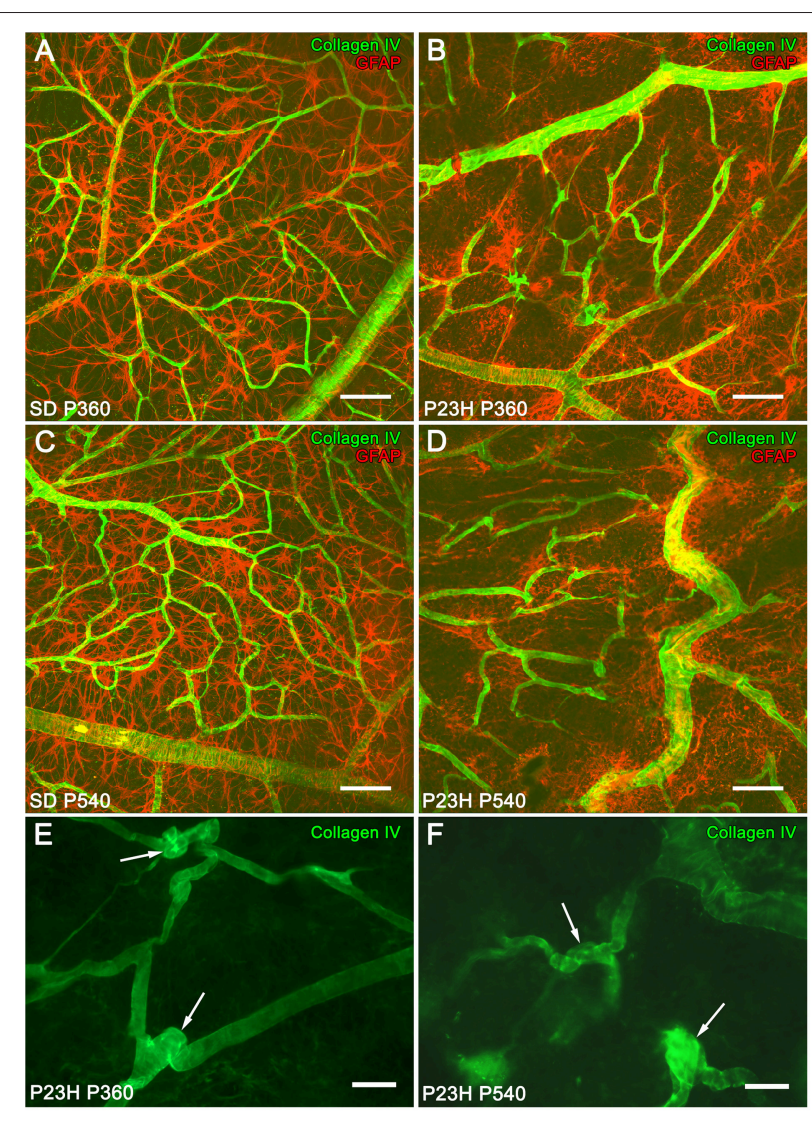

FIGURE 4 | Superficial vascular plexus in SD and $\mathrm{P} 23 \mathrm{H}$ rat retinas. Whole-mounted retinas from SD rats $(\mathbf{A}, \mathbf{C})$ and $\mathrm{P} 23 \mathrm{H}$ rats (B,D-F) at $\mathrm{P} 360$ (A,B,E), and P540 (C,D,F), stained for collagen IV (green) and GFAP (red) in order to show the relationship between blood vessels and astrocytes, respectively, during retinal degeneration. During aging, blood vessels in $\mathrm{P} 23 \mathrm{H}$ rat retinas $(\mathbf{B}, \mathbf{D})$ suffered alterations related to astrocyte changes that were unobserved in SD rats $(\mathbf{A}, \mathbf{C})$. Note the formation of blood vessel tangles at P360 (E, arrows) and P540 (F, arrows). Scale bar: $100 \mu \mathrm{m}$ (A,D), $40 \mu \mathrm{m}$ (E,F).

the retina of $\mathrm{P} 23 \mathrm{H}$ rats, as compared to the control animals at the ages of 4 and 12 months, respectively (ANOVA, Bonferroni's test, $P<0.001$ in both cases). Protein expression analysis also showed significantly greater GFAP levels in P360 vs. $\mathrm{P} 120 \mathrm{P} 23 \mathrm{H}$ rat retinas (ANOVA, Bonferroni's test, $P<0.01$ ), indicating that GFAP expression increased in $\mathrm{P} 23 \mathrm{H}$ rats during retinal degeneration. This age-related GFAP overexpression in $\mathrm{P} 23 \mathrm{H}$ rats was in parallel with the higher GFAP immunoreactivity observed in both astrocytes and Müller cells (Figures 3, 6).

\section{Expanded Müller Cell Processes in P23H Rat Retinas}

Müller cells span across the entire thickness of the neural retina and are essential in maintaining the neuroretinal architecture. In order to assess glial remodeling in degenerative $\mathrm{P} 23 \mathrm{H}$ rat retinas, GFAP immunoreactivity was analyzed in the ONL of whole-mounted retinas from $\mathrm{SD}$ and $\mathrm{P} 23 \mathrm{H}$ rats (Figure 8). In normal retinas, specific GFAP staining was absent in the ONL throughout the retina. However, in diseased retinas, the considerable loss of photoreceptors within the ONL was linked to the appearance of hypertrophied side branches of Müller cells into the outermost photoreceptor layer. At 4 and 12 months of age, apical GFAP-positive Müller cell processes were arranged in clusters, forming characteristic firework-like structures (Figures 8A-C). This peculiar distribution of Müller cell processes in the ONL was not present at 16 months of age (Figure 8D).

At 12 months of age in $\mathrm{P} 23 \mathrm{H}$ rats, whole-mount retinas showed that most of the cones exhibited a short morphology, indicating a degenerated state (Figures $\mathbf{9 A , B}$, arrowheads). The loss of rod photoreceptors altered the cone mosaic in the ONL. The regular distribution and orientation of cones was disrupted by the appearance of ring-like shaped areas of cone degeneration (Figures 9C,D). A double staining with GFAP and $\gamma$-transducin for simultaneous labeling of reactive Müller and cone cells showed a spatial correlation between ring-like shaped areas of cone cells and firework-like structures of Müller cell apical processes in $\mathrm{P} 360 \mathrm{P} 23 \mathrm{H}$ rats (Figures 9B,C). It is interesting to note that some of the cones arranged in parallel on the Müller cell processes showed a normal morphology, with long axons and well-defined outer segments (Figures 9E,F, arrowheads). The morphology of normal and degenerating cones in vertical retinal sections from a $\mathrm{SD}$ and $\mathrm{P} 23 \mathrm{H}$ rat retinas is shown in Supplementary Figure 1.

\section{DISCUSSION}

The response of the retina to injury results in a set of cell signals that lead to morphological and functional changes, including controlled cell death, and retinal remodeling (Marc et al., 2003; Jones and Marc, 2005; Cuenca et al., 2014). In this context, glial cells play a critical role, and the inflammatory response to injury can be decisive for maintaining the health of the retina or its degeneration (Bringmann et al., 2006; Bringmann and Wiedemann, 2012; Noailles et al., 2014; Hippert et al., 2015). Nevertheless, only a handful of longitudinal studies have considered gliosis in the retina. The current study provides evidence of the common and distinctive features of macroglial changes during retinal degeneration in the $\mathrm{P} 23 \mathrm{H}$ rat model of $\mathrm{RP}$.

In $\mathrm{P} 23 \mathrm{H}$ rats, retinal astrocytes were activated, proliferated, exhibited enlarged soma and thickened processes, and increased GFAP immunoreactivity. In many mammalian retinas, the density and morphology of astrocytes are strongly influenced by the nearby axons from ganglion cells, and a loss of retinal ganglion cell axons has been linked to a reduced density of astrocytes (Karschin et al., 1986; Gargini et al., 1998). In normal, healthy retinas, astrocytes are densely packed around blood vessels, with larger cells around the veins and smaller ones surrounding the arteries (Jammalamadaka et al., 2015). Here, we showed that retinal astrocyte density in both $\mathrm{SD}$ and $\mathrm{P} 23 \mathrm{H}$ rats gradually increased from the periphery toward the center of the retina, likely following the center to periphery decrease in retinal neuronal and blood vessel density.

Previous studies have reported that the number of astrocytes in the Wistar rat retina increases between 3 and 9 months and decreases between 9 and 12 months (Mansour et al., 2008). A 

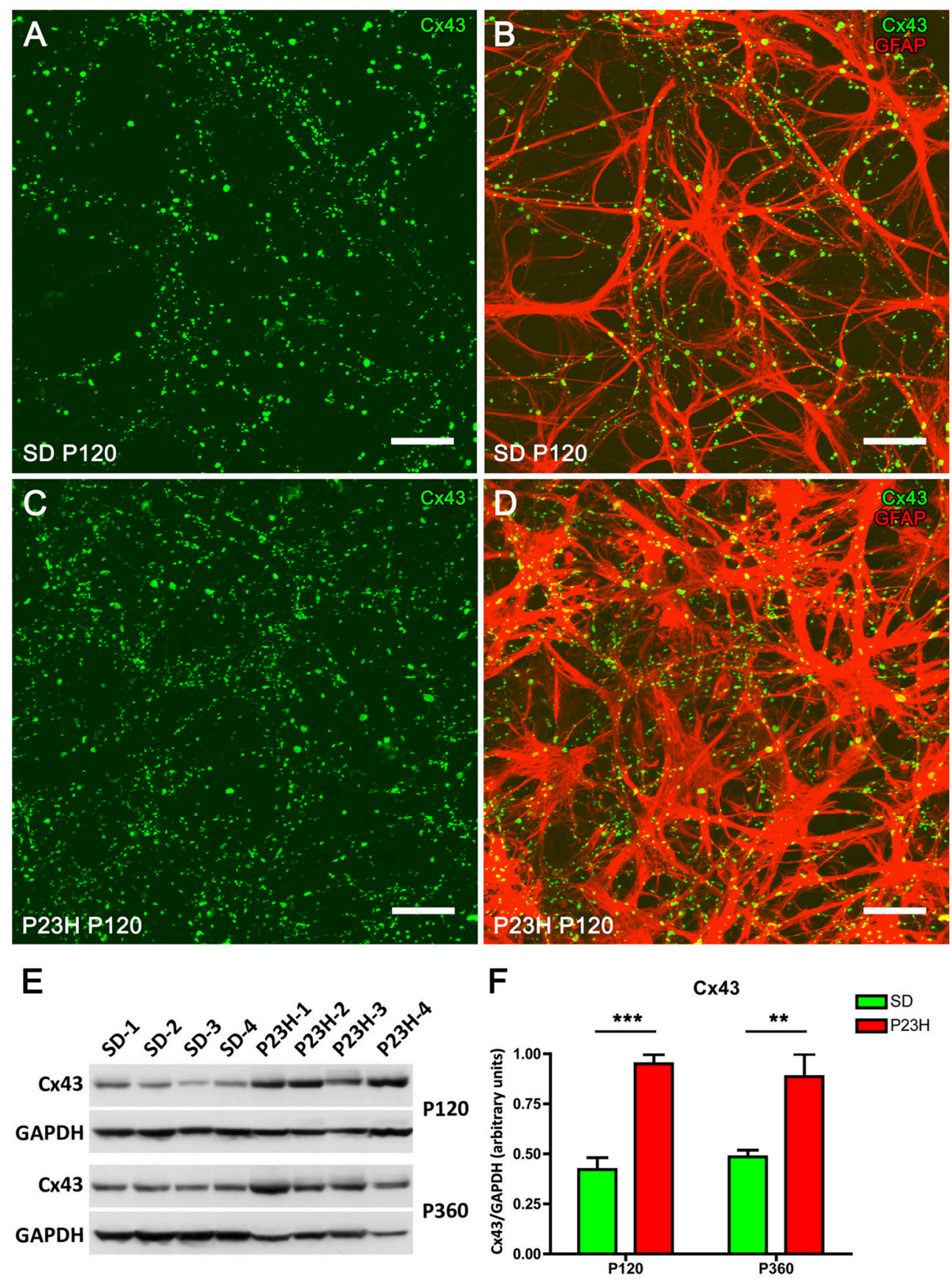

FIGURE 5 | Connexin 43 expression in SD and P23H rat retinas. Whole-mounted retinas from a SD rat (A,B) and a P23H rat (C,D) at P120. Connexin 43 (Cx43, green) and GFAP immunolabeling (red) show the relationship between retinal astrocytes and Cx43-immunoreactive (Cx43-IR) puncta. Note that Cx43-IR puncta are located along GFAP-IR astrocyte processes (B,D) and are more numerous in $\mathrm{P} 23 \mathrm{H}$ rat retinas $(\mathbf{C}, \mathbf{D})$, as compared to the control SD rat retinas $(\mathbf{A}, \mathbf{B})$. Scale bar: $20 \mu \mathrm{m}$. (E) Detection of Cx43 (43 kDa) in P23H rat retinas and SD controls by Western blotting at P120 and P360. GAPDH (36 kDa) levels are shown as loading controls. (F) The amount of $\mathrm{C} \times 43$ protein present in each band was densitometrically measured and the value obtained for each sample was normalized to GAPDH levels. Bars represent the average \pm SEM $(n=4) .{ }^{* *} P<0.01 ;{ }^{* \star *} P<0.001$

similar age-related decrease in the number of astrocytes has been observed in the human retina (Ramírez et al., 2001). Our results revealed a slight, progressive increase in astrocyte density in rats at 4,12 , or 16 months of age. On the other hand, in both
$\mathrm{SD}$ and $\mathrm{P} 23 \mathrm{H}$ rats, astrocyte density was significantly lower in adult rats as compared to that observed at P18. This can be attributed, at least partially, to the increase in the relative size of the retina during the postnatal development. The decline in 


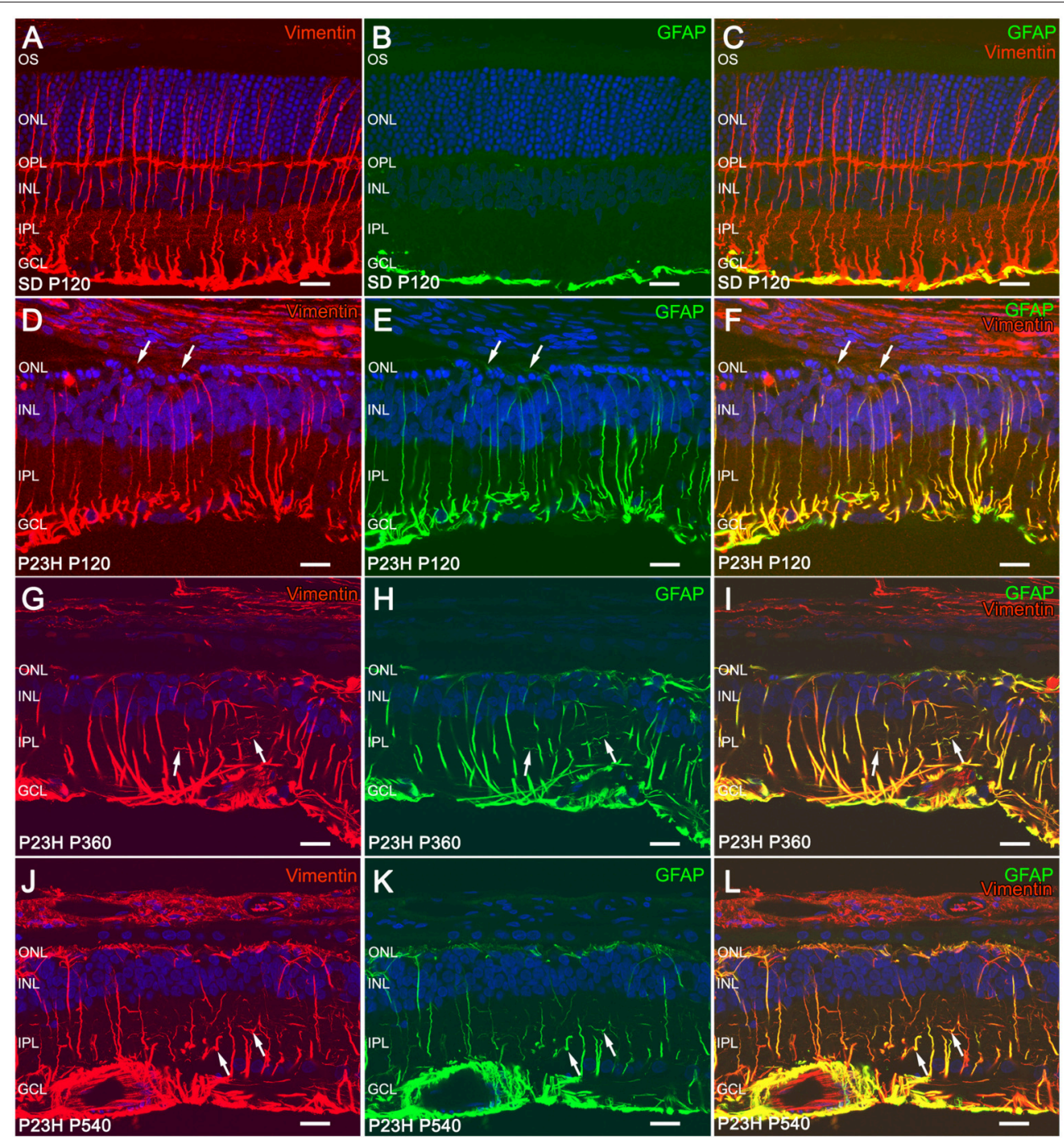

FIGURE 6 | Immunofluorescence of vimentin and GFAP in SD and P23H rat retinas. Vertical retinal sections from P120 SD rats (A-C) and P23H rats at P120 (A-F), P360 (G-I), and P540 (J-L). Nuclei were stained with the nuclear marker TO-PRO 3 (blue). Immunostaining with GFAP (green) and vimentin (red) shows reactive changes in Müller cells associated with retinal degeneration in $\mathrm{P} 23 \mathrm{H}$ rats. All images were collected from the medial area of the retina. ONL, outer nuclear layer; OPL, outer plexiform layer; INL, inner nuclear layer; IPL, inner plexiform layer; GCL, ganglion cell layer. Scale bar: $20 \mu \mathrm{m}$.
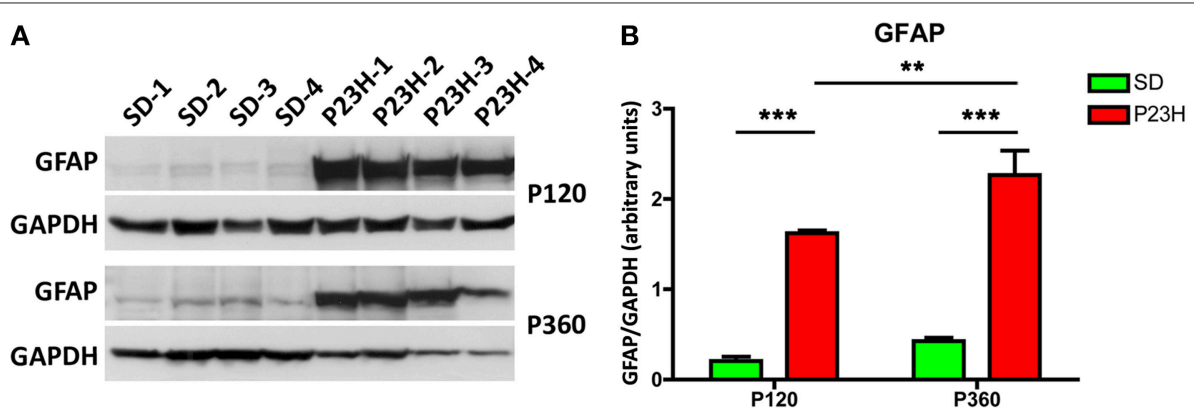

FIGURE 7 | GFAP expression in SD and P23H rat retinas. (A)Detection of GFAP (apparent molecular weight of $55 \mathrm{kDa}$ ) in P23H rat retinas and SD controls by Western blotting at P120 and P360. GAPDH (36 kDa) levels are shown as loading controls. (B) The amount of GFAP protein present in each band was densitometrically measured and the value obtained for each sample was normalized to GAPDH levels. Bars represent the average \pm SEM $(n=4) .{ }^{* *} P<0.01$; ${ }^{* \star *} P<0.001$ 

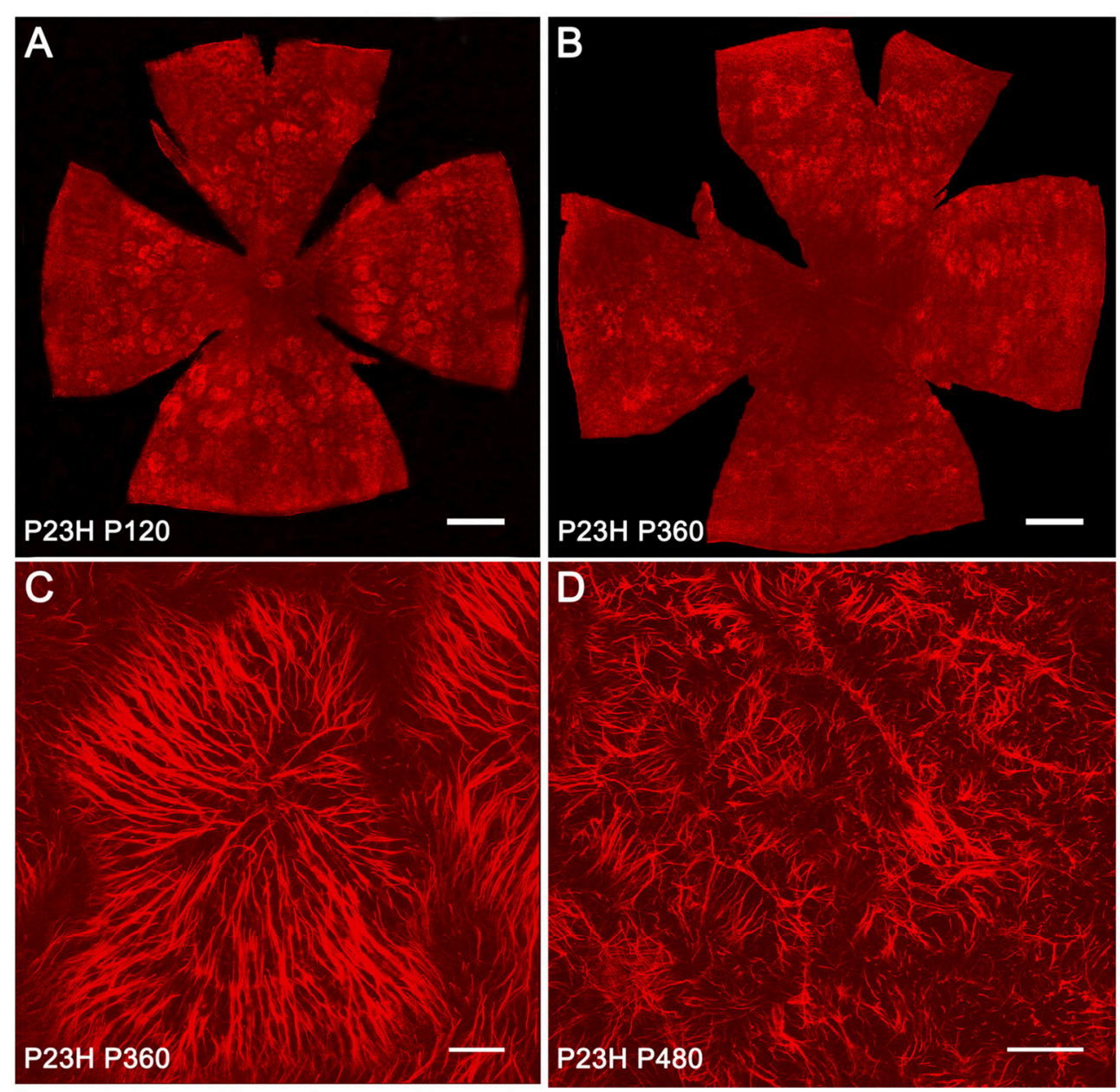

FIGURE 8 | GFAP-positive Müller cell apical processes in P23H rat retinas. Whole-mounted retinas from P23H rats at P120 (A), P360 (B,C), and P480 (D), showing GFAP-positive Müller cell processes distributed in the ONL. The retinas were flat-mounted with the photoreceptor layer facing up. Note the characteristic firework-like structures generated by Müller cells. Scale bar: $1 \mathrm{~mm}$ (A,B), $40 \mu \mathrm{m}$ (C), $100 \mu \mathrm{m}$ (D).

the number of astrocytes from early postnatal age may also be associated with a reduction in the number of retinal ganglion cells during the postnatal development. Previous studies have reported a significant decrease in ganglion cell numbers in the retina of newborn rats during the early weeks of the postnatal period (Perry et al., 1983).

It is assumed that reactive astrogliosis occurs in response to all forms of CNS injury or disease. However, gliotic changes in the degenerating retina may have very different features, depending upon the etiology, severity, and duration of the disease (Ridet et al., 1997; Sofroniew, 2005). Degenerative retinal diseases have been associated with both increases and decreases in astrocyte density. Decreases in the number of astrocytes have been observed in AMD (Ramírez et al., 2001) and during streptozotocin (STZ)-induced diabetes (Ly et al., 2011). The loss of astrocytes is also correlated with the development of pathological retinal neovascularization (Dorrell et al., 2010). On the contrary, no changes or increases in astrocyte density have been described in glaucoma (Wang et al., 2002; Formichella et al.,
2014). Our results indicated an increase in astrocyte cell number in $\mathrm{P} 23 \mathrm{H}$ rat retinas, as compared to control SD rats at 4 and 12 months of age, when the retina is undergoing a dramatic remodeling as a consequence of retinal degeneration. However, no changes in the number of these cells were observed between $\mathrm{SD}$ and $\mathrm{P} 23 \mathrm{H}$ at 16 month of age, probably due to the slowdown of the degenerative process in the $\mathrm{P} 23 \mathrm{H}$ rat retina from 12 to 16 months. According to this idea, it has been described subtle morphological changes in the $\mathrm{P} 23 \mathrm{H}$ line 1 rat retina between 12 and 18 months of degeneration (Pinilla et al., 2015).

The function of astrogliosis is anything but clear, although it has been linked to both protective and harmful effects (Ridet et al., 1997; Sofroniew, 2005). In the acute stage, astrocyte activation is believed to have a beneficial role, boosting the cytoarchitectural remodeling needed to enable glial cells to conserve tissue integrity by restricting the site of the lesion and enhancing their essential neuroprotective function. It has been demonstrated that, after an insult, reactive astrocytes demarcate damaged tissue, restrict inflammation, stimulate the repair of 

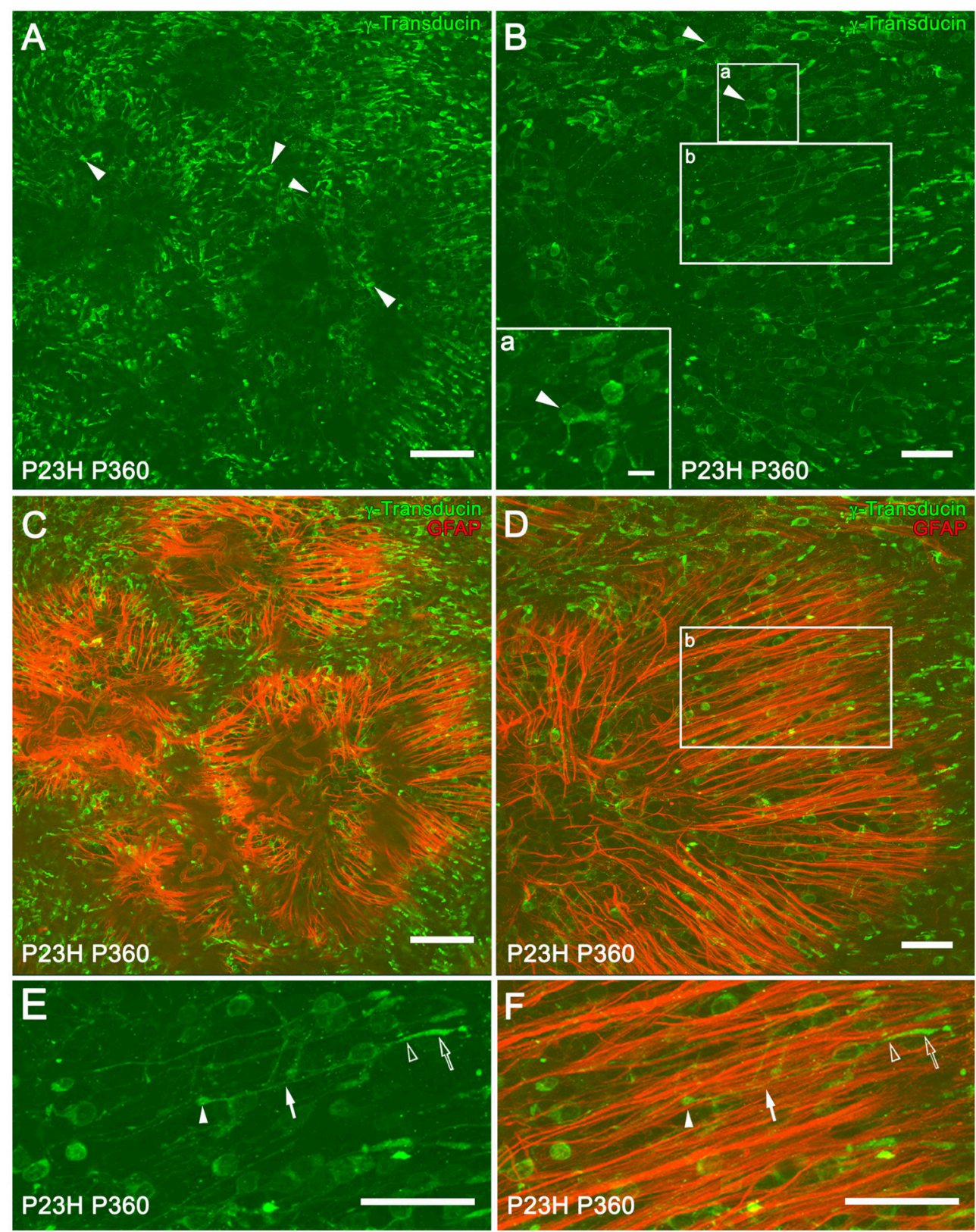

FIGURE 9 | Müller and cone cell interactions in P23H rat retinas. Whole-mounted retinas from P360 P23H rats showing single (A,B) and double (C,D) staining with $\gamma$-transducin (green) and GFAP (red) for labeling cone and reactive Müller cells, respectively. The retinas were flat-mounted with the photoreceptor layer facing up. Note the presence of degenerating cones with short outer segments and axons (A,B, arrowheads). High magnification of a degenerated cone is shown in (B) (lower left corner, inset a). (E,F) Magnification of (B,D) (inset b), respectively, showing cones with normal morphology [E, outer segment (empty arrow), inner segment (empty arrowhead), axons (arrow), and pedicles (arrowhead)] and Müller cell apical processes (red) arranged in parallel to the cones (F). Scale bar: $100 \mu \mathrm{m}(\mathbf{A}, \mathbf{C}), 10 \mu \mathrm{m}$ (Inset a), $40 \mu \mathrm{m}$ (B,D-F).

the blood-brain barrier, counteract edema, and protect neurons and neural function (Sofroniew, 2005). Conversely, prolonged activation can interfere with neuronal survival and regeneration.

Using antibodies against $\mathrm{Cx} 43$, we observed that $\mathrm{Cx} 43$-IR puncta were closely associated with GFAP-IR astrocyte processes at the GCL in both SD and $\mathrm{P} 23 \mathrm{H}$ rats. These results are in accordance with previous studies showing Cx43-IR puncta following GFAP-IR astrocyte processes on the inner surface of the rat retina (Kerr et al., 2010), and imply that the gap junctions formed by retinal astrocytes contain Cx43. Cx43-IR was previously detected in the GCL of rat retinas (Janssen-Bienhold et al., 1998). In humans, Cx43-IR has been found on GFAPpositive astrocytes in the retinal GCL and on the optic nerve head (Kerr et al., 2011). In P23H rat retinas, the density of Cx43IR puncta within the GCL and the GFAP protein expression were greater than in $\mathrm{SD}$ rat retinas. Increased $\mathrm{Cx} 43$ expression 
has been previously described following acute injury to the CNS (Lee et al., 2005; Nakase et al., 2006; Haupt et al., 2007) and in neurodegenerative diseases (Rufer et al., 1996; Vis et al., 1998). In glaucomatous eyes, increased Cx43-IR was observed in the peripapillary and mid-peripheral retina, in association with glial activation (Kerr et al., 2011). These observations may suggest a role for $\mathrm{Cx} 43$ in the pathogenesis of neurodegeneration. The higher expression of $\mathrm{Cx} 43$ and the increase in Cx43-IR puncta observed in $\mathrm{P} 23 \mathrm{H}$ rats were in correlation with the astrocyte cell hypertrophy observed in these animals. The main features of this hypertrophy are the elongation and proliferation of astrocyte processes, as well as the swelling of both cell bodies and processes, which is reflected in the complexity of the astrocytic network. In this context, because the number of astrocytes increased $20 \%$ and $23 \%$ in $\mathrm{P} 120$ and $\mathrm{P} 360 \mathrm{P} 23 \mathrm{H}$ rat retinas, respectively, as compared to control animals and the increase in $\mathrm{Cx} 43$ expression levels detected by Western blot was much higher (125 and $82 \%$ respectively), we suggest an increment of Cx43 expression per astrocyte. The overall increase in Cx43 could be the consequence of both the increased number of astrocytes and of their complexity in order to maintain the communication between adjacent cells throughout gap-junctions.

It is assumed that retinal diseases and injuries upregulate the GFAP, as well as additional intermediate filament proteins; this is thought to occur primarily in the Müller cells (Fisher and Lewis, 2003; Bringmann et al., 2006; Bringmann and Wiedemann, 2012). Thus, a common feature of all retinal diseases, including RP, glaucoma, $\mathrm{DR}$, and $\mathrm{AMD}$ in both animal models and humans, is the presence of a high level of GFAP in Müller cells (Madigan et al., 1994; Strettoi et al., 2002; Wang et al., 2002; Gerhardinger et al., 2005; Inman and Horner, 2007; Vogler et al., 2014; Hippert et al., 2015). This effect has been related to modifications in a potassium channel referred to as KCNQ5, suggesting a relationship between cytoskeletal proteins such as GFAP, and membrane proteins, such as potassium channels (Caminos et al., 2015). In addition to the increase in intermediate filament proteins, reactive Müller cells may become hypertrophied, resulting in a proliferation of fibrous processes on the outer edge of the retina (Fisher and Lewis, 2003; Marc and Jones, 2003; Gargini et al., 2007; Ray et al., 2010; Cuenca et al., 2014). The expanded Müller cell processes occupy the space left by the dying photoreceptors. We observed that GFAP immunoreactivity within Müller cells was markedly greater in $\mathrm{P} 23 \mathrm{H}$ rats than that observed in agematched control rats. In normal retinas, GFAP immunoreactivity was not detected, while diseased retinas showed intense GFAP immunoreactivity within the entire cell, from their end-feet to the outer limiting membrane. Moreover, hypertrophied branches of Müller cells were observed into the ONL of diseased retinas.

In parallel with the immunohistochemistry data, Western blotting results showed a large increase in GFAP protein expression in the retina of $\mathrm{P} 23 \mathrm{H}$ rats, as compared to the control animals. This increment reflects GFAP expression in the activated Müller cells. However, it is important to note that the astrocytic hyperplasia and hypertrophy observed in the degenerative retina of $\mathrm{P} 23 \mathrm{H}$ rats also contribute to the upregulation of GFAP expression. Additionally, in $\mathrm{P} 23 \mathrm{H}$ rat retinas, GFAP expression also increases with the age of the animal, indicating enhanced activation of glial cells in the advanced stages of retinal degeneration. The function of increased GFAP expression in Müller cells is unknown, although is thought to help stabilize the newly formed terminal processes of Müller cells and provide resistance to mechanical stress (Lundkvist et al., 2004; Verardo et al., 2008). Furthermore, increased levels of GFAP would seem to be essential for a multitude of responses during Müller cell gliosis, such as the formation of glial scars, neurite growth, infiltration of monocytes, neovascularization, and the integration of cells in retinal transplants, as all these characteristics were found to be attenuated in GFAP- and vimentin-deficient mice, which are an experimental animal model of retinal detachment (Lewis and Fisher, 2003; Nakazawa et al., 2007; Bringmann et al., 2009).

The cytoarchitecture of the outer nuclear layer is, at least in part, maintained by a network of heterotypic adherens junction complexes that form the outer limiting membrane (OLM) (Williams et al., 1990). These junctions connect the inner segments of photoreceptors to the apical processes of Müller cells, and thus photoreceptor death is likely to disrupt the OLM, and compromise the orientation and polarity of the photoreceptors (Hippert et al., 2015). In this study, the regular distribution and orientation of cone cells was disrupted by the appearance of ring-shaped areas of cone degeneration, with Müller cell apical processes forming clusters that resembled fireworks. This peculiar disposition of cones and apical Müller cell processes has been previously described in the S334ter-line-3 rat (Lee et al., 2011; Ji et al., 2015) and the P23H line 1 rat (García-Ayuso et al., 2013) models of RP. In agreement with previous studies (Cuenca et al., 2004, 2014; Lu et al., 2013), as photoreceptor degeneration progressed, cone morphology underwent progressive changes, including the shortening of both outer segments and axons. However, our results show for the first time that Müller cell apical processes are arranged parallel to some cones, which retain normal morphology in advanced stages of retinal degeneration. We also show that the spatial correlation between ring-like shaped areas of cone cells and firework-like structures of Müller cell apical processes are transient structures that disappear in late stages of retinal degeneration.

One can hypothesize that the loss of photoreceptors in this $\mathrm{RP}$ model, the $\mathrm{P} 23 \mathrm{H}$ rat, induces changes in retinal vasculature (Villegas-Pérez et al., 1998; Pennesi et al., 2008), which, in turn, may induce the activation of astrocytes and Müller cells. However, given that retinal macroglia is essential for the maintenance of retinal homeostasis, morphological changes, and activation of astrocytes and Müller cells can induce inner retinal remodeling (Marc et al., 2003; Cuenca et al., 2004, 2014; Jones and Marc, 2005; Puthussery and Taylor, 2010; Jones et al., 2012), including ganglion cell degeneration (Jones et al., 2003; GarcíaAyuso et al., 2010; Kolomiets et al., 2010). The disruption of blood vessels can affect the normal oxygen and nutrient supply to retinal cells, and thereby accelerate the progress of retinal degeneration. Most likely, inner retinal remodeling is mediated by changes in both retinal vasculature and macroglial cells after photoreceptor death in retinitis pigmentosa. 


\section{AUTHOR CONTRIBUTIONS}

Conception and design of the work: NC. Data acquisition and analysis: LF, LC. Data interpretation: LF, PL, IP, LC, NC. Drafting of the manuscript: LF, LC, PL, IP, NC.

\section{ACKNOWLEDGMENTS}

This research was supported by grants from the Spanish Ministry of Economy and Competitiveness-FEDER (BFU2012-36845), Instituto de Salud Carlos III (RETICS-FEDER RD12/0034/0010), Organización Nacional de Ciegos Españoles (ONCE), and FUNDALUCE.

\section{REFERENCES}

Anderson, P. J., Watts, H., Hille, C., Philpott, K., Clark, P., Gentleman, M. C., et al. (2008). Glial and endothelial blood-retinal barrier responses to amyloid-beta in the neural retina of the rat. Clin. Ophthalmol. 2, 801-816. doi: 10.2147/OPTH.S3967

Azevedo, F. A., Carvalho, L. R., Grinberg, L. T., Farfel, J. M., Ferretti, R. E., Leite, R. E., et al. (2009). Equal numbers of neuronal and nonneuronal cells make the human brain an isometrically scaled-up primate brain. J. Comp. Neurol. 513, 532-541. doi: 10.1002/cne.21974

Berson, E. L., Rosner, B., Sandberg, M. A., and Dryja, T. P. (1991). Ocular findings in patients with autosomal dominant retinitis pigmentosa and a rhodopsin gene defect (Pro-23-His). Arch. Ophthalmol. 109, 92-101. doi: 10.1001/archopht.1991.01080010094039

Bringmann, A., Grosche, A., Pannicke, T., and Reichenbach, A. (2013). GABA and glutamate uptake and metabolism in retinal glial (Muller) cells. Front. Endocrinol. (Lausanne) 4:48. doi: 10.3389/fendo.2013.00048

Bringmann, A., Iandiev, I., Pannicke, T., Wurm, A., Hollborn, M., Wiedemann, P., et al. (2009). Cellular signaling and factors involved in Muller cell gliosis: neuroprotective and detrimental effects. Prog. Retin. Eye Res. 28, 423-451. doi: 10.1016/j.preteyeres.2009.07.001

Bringmann, A., Pannicke, T., Grosche, J., Francke, M., Wiedemann, P., Skatchkov, S. N., et al. (2006). Muller cells in the healthy and diseased retina. Prog. Retin. Eye Res. 25, 397-424. doi: 10.1016/j.preteyeres.2006.05.003

Bringmann, A., and Wiedemann, P. (2012). Muller glial cells in retinal disease. Ophthalmologica 227, 1-19. doi: 10.1159/000328979

Caminos, E., Vaquero, C. F., and Martinez-Galan, J. R. (2015). Relationship between rat retinal degeneration and potassium channel KCNQ5 expression. Exp. Eye Res. 131, 1-11. doi: 10.1016/j.exer.2014.12.009

Chong, R. S., and Martin, K. R. (2015). Glial cell interactions and glaucoma. Curr. Opin. Ophthalmol. 26, 73-77. doi: 10.1097/ICU.0000000000000125

Coorey, N. J., Shen, W., Chung, S. H., Zhu, L., and Gillies, M. C. (2012). The role of glia in retinal vascular disease. Clin. Exp. Optom. 95, 266-281. doi: 10.1111/j.1444-0938.2012.00741.x

Cuenca, N., Fernández-Sánchez, L., Campello, L., Maneu, V., De La Villa, P., Lax, P., et al. (2014). Cellular responses following retinal injuries and therapeutic approaches for neurodegenerative diseases. Prog. Retin. Eye Res. 43, 17-75. doi: 10.1016/j.preteyeres.2014.07.001

Cuenca, N., Pinilla, I., Sauvé, Y., Lu, B., Wang, S., and Lund, R. D. (2004). Regressive and reactive changes in the connectivity patterns of rod and cone pathways of $\mathrm{P} 23 \mathrm{H}$ transgenic rat retina. Neuroscience 127, 301-317. doi: 10.1016/j.neuroscience.2004.04.042

Dorrell, M. I., Aguilar, E., Jacobson, R., Trauger, S. A., Friedlander, J., Siuzdak, G., et al. (2010). Maintaining retinal astrocytes normalizes revascularization and prevents vascular pathology associated with oxygen-induced retinopathy. Glia 58, 43-54. doi: 10.1002/glia.20900

Dryja, T. P., McEvoy, J. A., McGee, T. L., and Berson, E. L. (2000). Novel rhodopsin mutations Gly114Val and Gln184Pro in dominant retinitis pigmentosa. Invest. Ophthalmol. Vis. Sci. 41, 3124-3127.

\section{SUPPLEMENTARY MATERIAL}

The Supplementary Material for this article can be found online at: http://journal.frontiersin.org/article/10.3389/fncel. 2015.00484

Supplementary Figure 1 | Cone cells in SD and P23H rat retinas. Vertical retinal sections from a SD rat (A) and a $\mathrm{P} 23 \mathrm{H}$ rat at $\mathrm{P} 120$ stained with $\gamma$-transducin, showing the morphology of normal cones in SD rats and degenerating cones in $\mathrm{P} 23 \mathrm{H}$ rats. Note the typical cone shape in SD rats, where outer (empty arrows) and inner segments (empty arrowheads), axons (arrows) and pedicles (arrowheads) are clearly recognizable. By contrast, in $\mathrm{P} 23 \mathrm{H}$ rat retinas the cone outer segments are both short and swollen and very small in size, the axons are nor identifiable and pedicles seem to emerge directly from the cone cell bodies. Both images were collected from the central area of the retina, close to the optic nerve. Scale bar: $20 \mu \mathrm{m}$.

Dryja, T. P., McGee, T. L., Reichel, E., Hahn, L. B., Cowley, G. S., Yandell, D. W., et al. (1990). A point mutation of the rhodopsin gene in one form of retinitis pigmentosa. Nature 343, 364-366. doi: 10.1038/343364a0

Fisher, S. K., and Lewis, G. P. (2003). Muller cell and neuronal remodeling in retinal detachment and reattachment and their potential consequences for visual recovery: a review and reconsideration of recent data. Vision Res. 43, 887-897. doi: 10.1016/S0042-6989(02)00680-6

Formichella, C. R., Abella, S. K., Sims, S. M., Cathcart, H. M., and Sappington, R. M. (2014). Astrocyte reactivity: a biomarker for retinal ganglion cell health in retinal neurodegeneration. J. Clin. Cell Immunol. 5:188. doi: 10.4172/21559899.1000188

García-Ayuso, D., Ortín-Martínez, A., Jiménez-López, M., Galindo-Romero, C., Cuenca, N., Pinilla, I., et al. (2013). Changes in the photoreceptor mosaic of $\mathrm{P} 23 \mathrm{H}-1$ rats during retinal degeneration: implications for rod-cone dependent survival. Invest. Ophthalmol. Vis. Sci. 54, 5888-5900. doi: 10.1167/iovs.13-12643

García-Ayuso, D., Salinas-Navarro, M., Agudo, M., Cuenca, N., Pinilla, I., VidalSanz, M., et al. (2010). Retinal ganglion cell numbers and delayed retinal ganglion cell death in the P23H rat retina. Exp. Eye Res. 91, 800-810. doi: 10.1016/j.exer.2010.10.003

Gargini, C., Deplano, S., Bisti, S., and Stone, J. (1998). Evidence that the influence of ganglion cell axons on astrocyte morphology is mediated by action spike activity during development. Brain Res. Dev. Brain Res. 110, 177-184. doi: 10.1016/S0165-3806(98)00101-1

Gargini, C., Terzibasi, E., Mazzoni, F., and Strettoi, E. (2007). Retinal organization in the retinal degeneration 10 (rd10) mutant mouse: a morphological and ERG study. J. Comp. Neurol. 500, 222-238. doi: 10.1002/cne.21144

Gerhardinger, C., Costa, M. B., Coulombe, M. C., Toth, I., Hoehn, T., and Grosu, P. (2005). Expression of acute-phase response proteins in retinal Muller cells in diabetes. Invest. Ophthalmol. Vis. Sci. 46, 349-357. doi: 10.1167/iovs.04-0860

Harada, C., Harada, T., Quah, H. M., Maekawa, F., Yoshida, K., Ohno, S., et al. (2003). Potential role of glial cell line-derived neurotrophic factor receptors in Muller glial cells during light-induced retinal degeneration. Neuroscience 122, 229-235. doi: 10.1016/S0306-4522(03)00599-2

Haupt, C., Witte, O. W., and Frahm, C. (2007). Temporal profile of connexin 43 expression after photothrombotic lesion in rat brain. Neuroscience 144, 562-570. doi: 10.1016/j.neuroscience.2006.09.054

Hippert, C., Graca, A. B., Barber, A. C., West, E. L., Smith, A. J., Ali, R. R., et al. (2015). Muller glia activation in response to inherited retinal degeneration is highly varied and disease-specific. PLoS ONE 10:e0120415. doi: 10.1371/journal.pone.0120415

Illing, M. E., Rajan, R. S., Bence, N. F., and Kopito, R. R. (2002). A rhodopsin mutant linked to autosomal dominant retinitis pigmentosa is prone to aggregate and interacts with the ubiquitin proteasome system. J. Biol. Chem. 277, 34150-34160. doi: 10.1074/jbc.M204955200

Inman, D. M., and Horner, P. J. (2007). Reactive nonproliferative gliosis predominates in a chronic mouse model of glaucoma. Glia 55, 942-953. doi: 10.1002/glia.20516

Jammalamadaka, A., Suwannatat, P., Fisher, S. K., Manjunath, B. S., Höllerer, T., and Luna, G. (2015). Characterizing spatial distributions of 
astrocytes in the mammalian retina. Bioinformatics 31, 2024-2031. doi: 10.1093/bioinformatics/btv097

Janssen-Bienhold, U., Dermietzel, R., and Weiler, R. (1998). Distribution of connexin43 immunoreactivity in the retinas of different vertebrates. J. Comp. Neurol. 396, 310-321.

Ji, Y., Yu, W. Q., Eom, Y. S., Bruce, F., Craft, C. M., Grzywacz, N. M., et al. (2015). The effect of TIMP-1 on the cone mosaic in the retina of the rat model of retinitis pigmentosa. Invest. Ophthalmol. Vis. Sci. 56, 352-364. doi: 10.1167/iovs.14-15398

Jones, B. W., Kondo, M., Terasaki, H., Lin, Y., McCall, M., and Marc, R. E. (2012). Retinal remodeling. Jpn. J. Ophthalmol. 56, 289-306. doi: 10.1007/s10384-0120147-2

Jones, B. W., and Marc, R. E. (2005). Retinal remodeling during retinal degeneration. Exp. Eye Res. 81, 123-137. doi: 10.1016/j.exer.2005. 03.006

Jones, B. W., Watt, C. B., Frederick, J. M., Baehr, W., Chen, C. K., Levine, E. M., et al. (2003). Retinal remodeling triggered by photoreceptor degenerations. J. Comp. Neurol. 464, 1-16. doi: 10.1002/cne.10703

Karschin, A., Wässle, H., and Schnitzer, J. (1986). Shape and distribution of astrocytes in the cat retina. Invest. Ophthalmol. Vis. Sci. 27, 828-831.

Kaushal, S., and Khorana, H. G. (1994). Structure and function in rhodopsin. 7. Point mutations associated with autosomal dominant retinitis pigmentosa. Biochemistry 33, 6121-6128. doi: 10.1021/bi00186a011

Kerr, N. M., Johnson, C. S., De Souza, C. F., Chee, K. S., Good, W. R., Green, C. R., et al. (2010). Immunolocalization of gap junction protein connexin43 (GJA1) in the human retina and optic nerve. Invest. Ophthalmol. Vis. Sci. 51, 4028-4034. doi: 10.1167/iovs.09-4847

Kerr, N. M., Johnson, C. S., Green, C. R., and Danesh-Meyer, H. V. (2011). Gap junction protein connexin43 (GJA1) in the human glaucomatous optic nerve head and retina. J. Clin. Neurosci. 18, 102-108. doi: 10.1016/j.jocn.2010.06.002

Klaassen, I., Van Noorden, C. J., and Schlingemann, R. O. (2013). Molecular basis of the inner blood-retinal barrier and its breakdown in diabetic macular edema and other pathological conditions. Prog. Retin. Eye Res. 34, 19-48. doi: 10.1016/j.preteyeres.2013.02.001

Kolomiets, B., Dubus, E., Simonutti, M., Rosolen, S., Sahel, J. A., and Picaud, S. (2010). Late histological and functional changes in the $\mathrm{P} 23 \mathrm{H}$ rat retina after photoreceptor loss. Neurobiol. Dis. 38, 47-58. doi: 10.1016/j.nbd.2009.12.025

Kur, J., Newman, E. A., and Chan-Ling, T. (2012). Cellular and physiological mechanisms underlying blood flow regulation in the retina and choroid in health and disease. Prog. Retin. Eye Res. 31, 377-406. doi: 10.1016/j.preteyeres.2012.04.004

Lee, E. J., Ji, Y., Zhu, C. L., and Grzywacz, N. M. (2011). Role of Muller cells in cone mosaic rearrangement in a rat model of retinitis pigmentosa. Glia 59, 1107-1117. doi: 10.1002/glia.21183

Lee, I. H., Lindquist, E., Kiehn, O., Widenfalk, J., and Olson, L. (2005). Glial and neuronal connexin expression patterns in the rat spinal cord during development and following injury. J. Comp. Neurol. 489, 1-10. doi: 10.1002/cne.20567

Lewis, G. P., and Fisher, S. K. (2003). Up-regulation of glial fibrillary acidic protein in response to retinal injury: its potential role in glial remodeling and a comparison to vimentin expression. Int. Rev. Cytol. 230, 263-290. doi: 10.1016/S0074-7696(03)30005-1

Lu, B., Morgans, C. W., Girman, S., Lund, R., and Wang, S. (2013). Retinal morphological and functional changes in an animal model of retinitis pigmentosa. Vis. Neurosci. 30, 77-89. doi: 10.1017/S09525238130 00011

Luna, G., Lewis, G. P., Banna, C. D., Skalli, O., and Fisher, S. K. (2010). Expression profiles of nestin and synemin in reactive astrocytes and Muller cells following retinal injury: a comparison with glial fibrillar acidic protein and vimentin. Mol. Vis. 16, 2511-2523.

Lundkvist, A., Reichenbach, A., Betsholtz, C., Carmeliet, P., Wolburg, H., and Pekny, M. (2004). Under stress, the absence of intermediate filaments from Muller cells in the retina has structural and functional consequences. J. Cell Sci. 117, 3481-3488. doi: 10.1242/jcs.01221

Ly, A., Yee, P., Vessey, K. A., Phipps, J. A., Jobling, A. I., and Fletcher, E. L. (2011). Early inner retinal astrocyte dysfunction during diabetes and development of hypoxia, retinal stress, and neuronal functional loss. Invest. Ophthalmol. Vis. Sci. 52, 9316-9326. doi: 10.1167/iovs.11-7879
Machida, S., Kondo, M., Jamison, J. A., Khan, N. W., Kononen, L. T., Sugawara, T., et al. (2000). P23H rhodopsin transgenic rat: correlation of retinal function with histopathology. Invest. Ophthalmol. Vis. Sci. 41, 3200-3209.

Madigan, M. C., Penfold, P. L., Provis, J. M., Balind, T. K., and Billson, F. A. (1994). Intermediate filament expression in human retinal macroglia. Histopathologic changes associated with age-related macular degeneration. Retina 14, 65-74. doi: 10.1097/00006982-199401000-00014

Mansour, H., Chamberlain, C. G., Weible, M. W. II, Hughes, S., Chu, Y., and ChanLing, T. (2008). Aging-related changes in astrocytes in the rat retina: imbalance between cell proliferation and cell death reduces astrocyte availability. Aging Cell 7, 526-540. doi: 10.1111/j.1474-9726.2008.00402.x

Marc, R. E., and Jones, B. W. (2003). Retinal remodeling in inherited photoreceptor degenerations. Mol. Neurobiol. 28, 139-147. doi: 10.1385/MN:28:2:139

Marc, R. E., Jones, B. W., Watt, C. B., and Strettoi, E. (2003). Neural remodeling in retinal degeneration. Prog. Retin. Eye Res. 22, 607-655. doi: 10.1016/S13509462(03)00039-9

Nagy, J. I., and Rash, J. E. (2000). Connexins and gap junctions of astrocytes and oligodendrocytes in the CNS. Brain Res. Brain Res. Rev. 32, 29-44. doi: 10.1016/S0165-0173(99)00066-1

Nakase, T., Yoshida, Y., and Nagata, K. (2006). Enhanced connexin 43 immunoreactivity in penumbral areas in the human brain following ischemia. Glia 54, 369-375. doi: 10.1002/glia.20399

Nakazawa, T., Takeda, M., Lewis, G. P., Cho, K. S., Jiao, J., Wilhelmsson, U., et al. (2007). Attenuated glial reactions and photoreceptor degeneration after retinal detachment in mice deficient in glial fibrillary acidic protein and vimentin. Invest. Ophthalmol. Vis. Sci. 48, 2760-2768. doi: 10.1167/iovs.06-1398

Noailles, A., Fernandez-Sanchez, L., Lax, P., and Cuenca, N. (2014). Microglia activation in a model of retinal degeneration and TUDCA neuroprotective effects. J. Neuroinflammation 11, 186. doi: 10.1186/s12974-014-0186-3

Penn, J. S., Madan, A., Caldwell, R. B., Bartoli, M., Caldwell, R. W., and Hartnett, M. E. (2008). Vascular endothelial growth factor in eye disease. Prog. Retin. Eye Res. 27, 331-371. doi: 10.1016/j.preteyeres.2008.05.001

Pennesi, M. E., Nishikawa, S., Matthes, M. T., Yasumura, D., and Lavail, M. M. (2008). The relationship of photoreceptor degeneration to retinal vascular development and loss in mutant rhodopsin transgenic and RCS rats. Exp. Eye Res. 87, 561-570. doi: 10.1016/j.exer.2008.09.004

Perry, V. H., Henderson, Z., and Linden, R. (1983). Postnatal changes in retinal ganglion cell and optic axon populations in the pigmented rat. J. Comp. Neurol. 219, 356-368. doi: 10.1002/cne.902190309

Pinilla, I., Fernández-Sánchez, L., Segura, F. J., Sánchez-Cano, A. I., Tamarit, J. M., Fuentes-Broto, L., et al. (2015). Long time remodeling during retinal degeneration evaluated by optical coherence tomography, immunocytochemistry and fundus autofluorescence. Exp. Eye Res. doi: 10.1016/j.exer.2015.10.012. [Epub ahead of print].

Pinilla, I., Lund, R. D., and Sauvé, Y. (2005). Enhanced cone dysfunction in rats homozygous for the $\mathrm{P} 23 \mathrm{H}$ rhodopsin mutation. Neurosci. Lett. 382, 16-21. doi: 10.1016/j.neulet.2005.02.055

Puthussery, T., and Taylor, W. R. (2010). Functional changes in inner retinal neurons in animal models of photoreceptor degeneration. Adv. Exp. Med. Biol. 664, 525-532. doi: 10.1007/978-1-4419-1399-9_60

Ramírez, J. M., Ramírez, A. I., Salazar, J. J., De Hoz, R., and Triviño, A. (2001). Changes of astrocytes in retinal ageing and age-related macular degeneration. Exp. Eye Res. 73, 601-615. doi: 10.1006/exer.2001.1061

Ray, A., Sun, G. J., Chan, L., Grzywacz, N. M., Weiland, J., and Lee, E. J. (2010). Morphological alterations in retinal neurons in the S334ter-line3 transgenic rat. Cell Tissue Res. 339, 481-491. doi: 10.1007/s00441-009-0916-5

Reichenbach, A., and Bringmann, A. (2013). New functions of Muller cells. Glia 61, 651-678. doi: 10.1002/glia.22477

Remé, C. E., Grimm, C., Hafezi, F., Marti, A., and Wenzel, A. (1998). Apoptotic cell death in retinal degenerations. Prog. Retin. Eye Res. 17, 443-464. doi: 10.1016/S1350-9462(98)00009-3

Ridet, J. L., Malhotra, S. K., Privat, A., and Gage, F. H. (1997). Reactive astrocytes: cellular and molecular cues to biological function. Trends Neurosci. 20, 570-577. doi: 10.1016/S0166-2236(97)01139-9

Rufer, M., Wirth, S. B., Hofer, A., Dermietzel, R., Pastor, A., Kettenmann, H., et al. (1996). Regulation of connexin-43, GFAP, and FGF-2 is not accompanied by changes in astroglial coupling in MPTP-lesioned, FGF-2-treated parkinsonian mice. J. Neurosci. Res. 46, 606-617. 
Shen, W., Li, S., Chung, S. H., and Gillies, M. C. (2010). Retinal vascular changes after glial disruption in rats. J. Neurosci. Res. 88, 1485-1499. doi: $10.1002 /$ jnr. 22317

Sofroniew, M. V. (2005). Reactive astrocytes in neural repair and protection. Neuroscientist 11, 400-407. doi: 10.1177/1073858405278321

Strettoi, E., Porciatti, V., Falsini, B., Pignatelli, V., and Rossi, C. (2002). Morphological and functional abnormalities in the inner retina of the $\mathrm{rd} / \mathrm{rd}$ mouse. J. Neurosci. 22, 5492-5504.

Vecino, E., Rodriguez, F. D., Ruzafa, N., Pereiro, X., and Sharma, S. C. (2015). Glia-neuron interactions in the mammalian retina. Prog. Retin. Eye Res. doi: 10.1016/j.preteyeres.2015.06.003. [Epub ahead of print].

Verardo, M. R., Lewis, G. P., Takeda, M., Linberg, K. A., Byun, J., Luna, G., et al. (2008). Abnormal reactivity of muller cells after retinal detachment in mice deficient in GFAP and vimentin. Invest. Ophthalmol. Vis. Sci. 49, 3659-3665. doi: 10.1167/iovs.07-1474

Villegas-Pérez, M. P., Lawrence, J. M., Vidal-Sanz, M., Lavail, M. M., and Lund, R. D. (1998). Ganglion cell loss in RCS rat retina: a result of compression of axons by contracting intraretinal vessels linked to the pigment epithelium. J. Comp. Neurol. 392, 58-77.

Vis, J. C., Nicholson, L. F., Faull, R. L., Evans, W. H., Severs, N. J., and Green, C. R. (1998). Connexin expression in Huntington's diseased human brain. Cell Biol. Int. 22, 837-847. doi: 10.1006/cbir.1998.0388

Vogler, S., Pannicke, T., Hollborn, M., Grosche, A., Busch, S., Hoffmann, S., et al. (2014). Muller cell reactivity in response to photoreceptor degeneration in rats with defective polycystin-2. PLoS ONE 8:e61631. doi: 10.1371/journal.pone.0061631

Wang, L., Cioff,, G. A., Cull, G., Dong, J., and Fortune, B. (2002). Immunohistologic evidence for retinal glial cell changes in human glaucoma. Invest. Ophthalmol. Vis. Sci. 43, 1088-1094.

Williams, D. S., Arikawa, K., and Paallysaho, T. (1990). Cytoskeletal components of the adherens junctions between the photoreceptors and the supportive Muller cells. J. Comp. Neurol. 295, 155-164. doi: 10.1002/cne.9029 50113

Zahs, K. R., Kofuji, P., Meier, C., and Dermietzel, R. (2003). Connexin immunoreactivity in glial cells of the rat retina. J. Comp. Neurol. 455, 531-546. doi: $10.1002 / \mathrm{cne} .10524$

Conflict of Interest Statement: The authors declare that the research was conducted in the absence of any commercial or financial relationships that could be construed as a potential conflict of interest.

Copyright ( 2015 Fernández-Sánchez, Lax, Campello, Pinilla and Cuenca. This is an open-access article distributed under the terms of the Creative Commons Attribution License (CC BY). The use, distribution or reproduction in other forums is permitted, provided the original author(s) or licensor are credited and that the original publication in this journal is cited, in accordance with accepted academic practice. No use, distribution or reproduction is permitted which does not comply with these terms. 